\title{
Epidemic pattern of hand-foot-and-mouth disease in Xi'an, China from 2008 through 2015
}

\author{
JiFeng Liu ${ }^{1} \mathbb{B}$, XiaoMei Xiang ${ }^{2}$, ZhongShu Pư ${ }^{3}$, Yong Long ${ }^{2}$, Dan Xiao², WeiLu Zhang ${ }^{2}$, Qian Li ${ }^{4}$, XiTong Li $^{4}$, \\ SiYao Li ${ }^{4}$, ZhongJun Shao ${ }^{2}$, XiaoLi Yang ${ }^{1}$ and YongMin Xiong ${ }^{1 *}$
}

\begin{abstract}
Background: Hand, foot and mouth disease (HFMD) is an infectious disease caused by enteroviruses that has a severely impair for those high incidence countries such as China.The current study aimed to investigate the epidemic pattern of HFMD by time and region in Northwestern China.

Methods: All reported HFMD cases from 2008 to 2015 were collected from local Disease Control and Prevention. The HFMD was diagnosed in accordance with the guidebook provided by the National Health and Family Planning Commission of the People's Republic of China.

Results: A total of 154,869 cases of probable HFMD were reported. The overall incidence of HFMD has been increased from 91.68 per 100/000 in 2008 to 335.64 per 100/000 in 2015.The case mortality is decreased from 0.014 per100/000 to 0.011 per 100/000 during the time period. Most HFMD (93.82\%) occurred in children younger than 5 years. The seasonal peak of HFMD infections occurred in April-July and September-November and Central regions of Xi'an city were the major locations of the clusters (incidence rate 245.75/100,000; relative risk 1.19, $P<0.01$ ). EVA71 was the predominant enterovirus serotype, accounting for 50.0\% of all reported HFMD cases since 2011.The most susceptible group infected by HFMD was children younger than 5 years, especially boys.

Conclusions: Incidence of HFMD has been increasing in the past few years, however, the case fatality is decreasing. Season and region shall be considered as influence factors in the prevention of HFMD.
\end{abstract}

Keywords: Hand-foot-and-mouth disease, Epidemic, Distribution, Serotype

\section{Background}

Hand-foot-and-mouth disease (HFMD) is a viral infectious disease caused by human enteroviruses. It is typically characterized by fever, sore throat, general malaise, and vesicular rash on the hands and feet, as well as exanthema on oral mucosa and tongue [1]. Two serotypes of enteroviruses, A71 (EVA71) and Coxsackie virus A16 (CVA16), regarded as the major causes for the repeated national HFMD outbreaks in China [2].

To achieve better control and prevention of HFMD, many studies have explored the epidemiological

\footnotetext{
* Correspondence: xiongym@mail.xjtu.edu.cn

'Institute of Endemic Diseases of School of Public Health, Health Science Center, Key Laboratory of Trace Elements and Endemic Diseases of National Health and Family Planning Commission, Xi'an Jiaotong University, No.76, YanTa West RD, Xi'an 710061, Shaanxi, China

Full list of author information is available at the end of the article
}

distribution pattern of HFMD in some areas of China [2-4], including the provinces of Guangdong [5, 6], Hainan [7], Guangxi [8], and Shaanxi [9]. The consensus of these studies was that most HFMD cases were children younger than five years, with boys having the higher incidence rate. However, regions of China have varied in the temporal and spatial distributions of high HFMD incidence rates, and also the predominate serotype.

Xi'an city is the capital of Shaanxi Province, an area that is continuously threatened seriously by HFMD [3]. Xi'an, locates at $33^{\circ} 42^{\prime}-34^{\circ} 45^{\prime} \mathrm{N}, 107^{\circ} 40^{\prime}-109^{\circ} 49^{\prime} \mathrm{E}$, the central of China, with a population size of 8.63 million, and contains 13 counties and districts [10]. The landscape of Xi'an is flat with climate of temperate continental monsoon, which is favorable for the transmission of HFMD. Outbreaks of HFMD occur frequently in Xi'an

(c) The Author(s). 2019 Open Access This article is distributed under the terms of the Creative Commons Attribution 4.0 International License (http://creativecommons.org/licenses/by/4.0/), which permits unrestricted use, distribution, and reproduction in any medium, provided you give appropriate credit to the original author(s) and the source, provide a link to the Creative Commons license, and indicate if changes were made. The Creative Commons Public Domain Dedication waiver (http://creativecommons.org/publicdomain/zero/1.0/) applies to the data made available in this article, unless otherwise stated. 
$[11,12]$, which has imposed a substantial disease burden for local government. To better control and prevent this disease, a clear epidemiological pattern of this disease is needed. However, until now, no study has systematically analyzed the temporal-spatial distribution of HFMD infections, and the association between different serotypes and severity of disease in Xi'an. Therefore, in the current study, we mainly aimed to explore the distribution pattern of HFMD by time period and region, and to identify the major enterovirus serotypes causing this disease.

\section{Methods}

\section{Data collection}

The surveillance data of HFMD in Xi'an city from 2008 to 2015 were obtained from Xi'an Center for Disease Control and Prevention (CDC). Disease-related demographic information, such as gender, occupation, age, date of diagnosis, and disease severity (mild or severe) were collected. In China, HFMD is a national class C notifiable communicable disease and all clinics are obliged to report HFMD cases to the local CDC within $24 \mathrm{~h}$. The HFMD web-based surveillance network comprises 105 clinics and local CDCs in 13 counties and districts in Xi'an. The HFMD was diagnosed in accordance with the guidebook provided by the National Health and Family Planning Commission of the People's Republic of China (version 2008). The CDC laboratory did PCR test through the surveillance program that each district send HFMD samples to city level CDC every month,which include the mild cases,the severe and death case sample. All of the laboratory tested cases were randomly selected by the clinics and district $\mathrm{CDC}$, and these cases composed of our study sample. Most of the HFMD cases are mild thus we could not collect all of the mild cases through the surveillance system, but died and severe cases were less and we tried our best to collect them, and also, not all of the HFMD cases could be included in our study.

\section{Specimen collection and virological investigations}

Throat swabs and urine and fecal samples were collected from outpatients and inpatients in each clinic and local center. Five microliters of viral RNA was extracted from each patient. Reverse transcription and real-time polymerase chain reaction (PCR) was performed to identify the infecting enterovirus using commercial enterovirus detection kits (Da An Gene, Guangzhou, China). The PCR kit we used was three monoplex PCR kits. The enterovirus infection results were classified into four groups in accordance with the manufacturer's instructions: EVA71-positive, CVA16-positive, pan-enterovirus, or enterovirus-negative. To ensure the reliability of results, all tests were conducted at the Xi'an CDC laboratory, with a biosafety level 2 .

\section{Seasonal variation analysis}

The monthly number of HFMD cases was used to calculate the seasonal indices from 2008 through 2015 in Xi'an City. The seasonal index was calculated as:

$$
S_{k}=\frac{x_{k}}{\bar{x}}, \text { where } x_{k}=\frac{N_{k}}{P_{k}} \text { and } \bar{x}=\frac{\sum_{i=1}^{n} N_{i}}{12 \times \sum_{i=1}^{n} P_{i}}
$$

The term $S_{k}$ denotes the seasonal index in month $k$, where $k=1,2, \ldots 12$. The term $x_{k}$ is the incidence rate in month $\mathrm{k}$; $\bar{x}$ is the mean incidence rate during the entire study period. $N_{k}$ is the number of cases in month $\mathrm{k}, P_{k}$ denotes the population in month $\mathrm{k}$, where $\mathrm{k}=1,2, \ldots 12$. The parameter $N_{i}$ denotes the number of cases in year $\mathrm{i}$, and $P_{i}$,means the population in year $\mathrm{i}$, where $i=1,2, \ldots$ 8 ,The parameter $n$ denotes the total number of years, which was 8 in this study. If all the seasonal indices in each month were close to 1 , this meant that no obvious seasonal fluctuation was detected.

\section{Secular trend analysis}

The annual HFMD incidence rates during 2008-2015 in Xi'an city were calculated and plotted to show the annual fluctuations in HFMD infections. The Cochran-Armitage trend test was employed to examine the temporal trends in annual HFMD incidence during 2008-2015. $Z>0$ denoted an increasing trend, while $Z<0$ denoted a declining trend. The trend was considered significant when $P$ was $<$ 0.05 . The Cochran-Armitage trend test was performed using SAS 9.2 (SAS Institute, USA).

\section{Spatial distribution analysis}

A spatial cluster analysis was used to analyze the spatial autocorrelation association of HFMD incidence based on the locations of study regions. The annual incidence of HFMD in each county or district was mapped for the years 2008 through 2015. Each region was marked with a different color on the county-level digital map.

A spatial cluster analysis of HFMD incidence rate from 2008 through 2015 was conducted to detect the high-risk areas of HFMD in Xi'an City. The relative risk (RR) of HFMD among different regional clusters was calculated to compare the difference in incidence rate among those regions. The most likely cluster was the area with the highest HFMD risk, and the secondary cluster indicated an area with the second-highest HFMD risk. A maximum cluster size of $30 \%$ of the study population was specified in the spatial cluster analysis. The spatial cluster analysis was performed using SatScan 7.0.3 (Information Management Services, Boston, MA, USA). 


\section{Enterovirus serotype distribution analysis}

The annual proportion of cases infected by the different enterovirus serotypes from 2008 through 2015 was calculated and plotted to show the distribution and variations in etiology of HFMD in Xi'an City. The median age, fatality rate due to HFMD, and proportion of severe cases infected by different enterovirus serotypes was calculated.

\section{Basic epidemiological and statistical analysis}

Descriptive statistics (distributions of age, gender, rates of incidence and mortality rate, fatality rate, and disease severity) were used to describe the epidemiological characteristics of HFMD. Chi-squares test was applied to compare the age and gender distributions of HFMD incidence rate.

\section{Results}

\section{Demographic incidence trend of HFMD}

There were 154,869 cases of probable HFMD infection reported in Xi'an city from 2008 through 2015. The average incidence and mortality rates were 235.01 and 0.041 per 100,000 , respectively (Table 1 ). The average fatalities rate was $0.017 \%$. The highest incidence rate of HFMD was observed in the years $2015(328.02 / 100,000)$, followed by the year $2010(325.23 / 100,000)$ (Table 3$)$. The mortality rate reached peak in the year $2012(0.071 / 100,000)$, and case fatality rate peaked in the year $2009(0.043 \%)$.

The trend in HFMD infections by age group was shown in Fig. 1. The age range of reported cases was 0.1 to 80 years, with a median age of 3.0 years. The ages of most cases of probable HFMD were in the range of 1-4 years, accounting for $86.53 \%$ of 134,013 cases. Approximately $93.82 \%$ cases were younger than 5 years.

Of the 154,869 probable HFMD cases, 92,193 (59.53\%) were males and 62,676 (40.47\%) were females (Table 2). The highest incidence rate of HFMD infection were observed in age groups of 1-year (6167.17/100,000), 2-year

Table 1 The annual reported HFMD cases, incidence rate, mortality rate, and case fatality rate in Xi'an City, China (2008-2015) ${ }^{\text {a }}$

\begin{tabular}{lllll}
\hline & Cases, $\mathrm{n}$ & Incidence/100,000 & Mortality/100,000 & Case fatalities, \% \\
\hline 2008 & 7065 & 91.53 & 0.013 & 0.014 \\
2009 & 11,533 & 149.00 & 0.065 & 0.043 \\
2010 & 25,200 & 325.23 & 0.065 & 0.020 \\
2011 & 12,374 & 146.13 & 0.024 & 0.016 \\
2012 & 25,348 & 298.17 & 0.071 & 0.024 \\
2013 & 19,918 & 233.09 & 0.012 & 0.005 \\
2014 & 25,257 & 294.06 & 0.047 & 0.016 \\
2015 & 28,174 & 328.02 & 0.035 & 0.011 \\
Total & 154,869 & 235.01 & 0.041 & 0.017 \\
\hline
\end{tabular}

${ }^{2}$ Data reported as number of cases, unless indicated otherwise

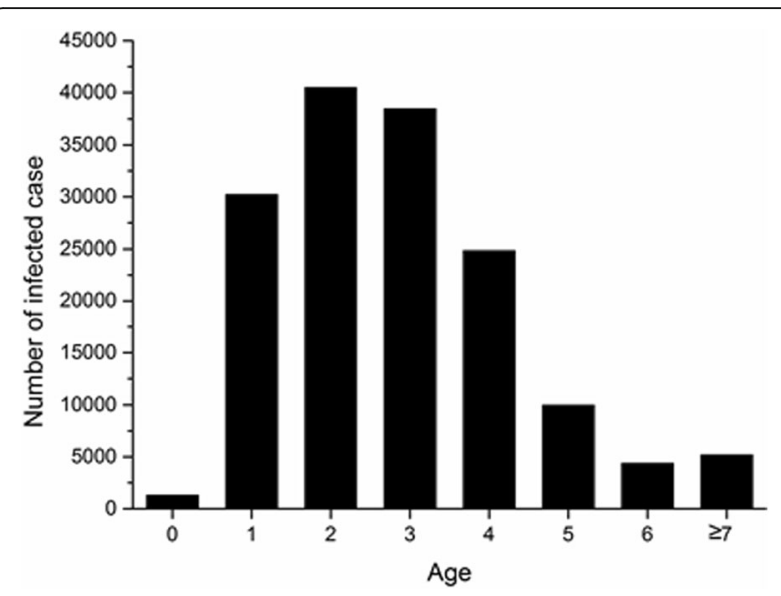

Fig. 1 Age distribution of HFMD infections overall during 2008-2015 in Xi'an City, China

(5368.42/100,000), and 3-year (5264.54/100,000). Males $(273.29 / 100,000)$ had higher HFMD incidence rate than females $(197.01 / 100,000)$ in Xi'an City $\left(X^{2}=11.996, P=\right.$ 0.001 , data not shown).

\section{Temporal distribution of HFMD incidence}

The seasonal variations in rate of HFMD infection are shown in Fig. 2. A small peak of HFMD infections (22.54\%) occurred during September and November, and a large peak occurred during April and July (66.11\%). The secular trend in HFMD infections was calculated based on the estimated annual incidence rate. A fluctuating but increasing temporal trend of incidence rate, together with declining trend of fatality rate due to HFMD were identified (Cochran-Armitage trend test, incidence rate: $Z=102.5, P<0.05$; mortality rate: $Z=-0.2, P>$ 0.05 ; case fatality rate: $Z=-2.3, P<0.05$ ).

\section{Spatial distribution of HFMD infections}

The spatial distribution of HFMD incidence rate based on the annual incidence rate at the county level in Xi'an City during 2008 and 2015 was illustrated in Fig. 3. Weiyang district had the highest average incidence rate during the entire period. The highest incidence rate of HFMD occurred in 2015 in Zhouzhi district (548.19/ $100,000)$, while the lowest rate occurred in 2008 in Zhouzhi county $(8.21 / 100,000)$ (Table 3$)$.

The spatial cluster analysis of HFMD incidence rate during 2008-2015 showed that Weiyang district and Gaoling county together constitute the cluster with the highest HFMD incidence rate (average annual incidence $=378.17 / 100,000 ; R R=1.81, P<0.01)$, followed by Yanta district and Chang'an district as the cluster with the second highest HFMD incidence rate (average annual incidence $=305.45 / 100,000, R R=1.52, P<0.01$; Fig. 4 ). 
Table 2 Incidence of HFMD infection per 100,000 by year, gender, and age from birth to 10 years

\begin{tabular}{|c|c|c|c|c|c|c|c|c|c|c|c|c|c|}
\hline & & Age, y & & & & & & & & & & & \\
\hline & & 0 & 1 & 2 & 3 & 4 & 5 & 6 & 7 & 8 & 9 & 10 & Total \\
\hline 2008 & Male & 436.53 & 1362.39 & 2380.90 & 2334.80 & 1578.39 & 506.05 & 273.32 & 131.29 & 84.11 & 64.75 & 1.98 & 109.67 \\
\hline & Female & 284.19 & 861.73 & 1676.18 & 1628.30 & 993.70 & 379.52 & 179.76 & 82.51 & 81.93 & 56.30 & 1.19 & 72.58 \\
\hline & Total & 363.30 & 1122.21 & 2042.83 & 1995.85 & 1297.89 & 445.35 & 228.43 & 109.68 & 83.15 & 60.97 & 1.60 & 91.68 \\
\hline 2009 & Male & 864.62 & 1893.24 & 4127.35 & 3698.19 & 1975.15 & 998.61 & 384.69 & 166.30 & 120.75 & 59.06 & 1.87 & 173.13 \\
\hline & Female & 547.43 & 1271.04 & 2963.49 & 2851.10 & 1498.59 & 741.71 & 244.91 & 121.82 & 96.57 & 96.46 & 1.94 & 123.69 \\
\hline & Total & 712.13 & 1594.76 & 3569.03 & 3291.81 & 1746.52 & 875.36 & 317.62 & 144.96 & 110.03 & 75.53 & 1.90 & 149.14 \\
\hline 2010 & Male & 1887.43 & 7925.33 & 8221.74 & 6875.22 & 3244.56 & 1364.83 & 585.62 & 224.68 & 191.91 & 146.11 & 4.88 & 378.75 \\
\hline & Female & 1353.95 & 5779.97 & 5801.57 & 5005.03 & 2485.78 & 967.01 & 440.81 & 153.46 & 137.04 & 107.38 & 4.28 & 268.87 \\
\hline & Total & 1630.95 & 6896.30 & 7060.84 & 5978.03 & 2880.54 & 1173.96 & 516.14 & 190.51 & 165.58 & 128.95 & 4.59 & 325.40 \\
\hline 2011 & Male & 1256.33 & 4463.24 & 4100.00 & 4236.90 & 2072.98 & 908.64 & 291.42 & 119.46 & 93.95 & 101.70 & 1.90 & 172.62 \\
\hline & Female & 849.54 & 3084.01 & 2855.33 & 3023.84 & 1412.37 & 650.47 & 302.90 & 89.48 & 73.06 & 99.20 & 1.49 & 118.73 \\
\hline & Total & 1060.16 & 3799.31 & 3501.12 & 3653.00 & 1755.03 & 784.32 & 296.94 & 105.03 & 83.89 & 100.59 & 1.70 & 146.35 \\
\hline 2012 & Male & 3392.07 & 9606.99 & 8990.30 & 8767.84 & 4431.84 & 1724.01 & 735.71 & 285.68 & 198.37 & 167.72 & 4.05 & 346.42 \\
\hline & Female & 2465.55 & 7645.50 & 6724.38 & 6450.22 & 3342.04 & 1351.23 & 527.40 & 289.08 & 153.35 & 190.89 & 4.06 & 247.14 \\
\hline & Total & 2952.52 & 8687.36 & 7923.16 & 7674.81 & 3917.19 & 1550.19 & 638.65 & 287.33 & 176.43 & 177.66 & 4.06 & 297.98 \\
\hline 2013 & Male & 3924.49 & 9695.87 & 5694.52 & 5831.32 & 2619.58 & 1110.64 & 423.59 & 130.45 & 69.86 & 123.11 & 2.81 & 269.20 \\
\hline & Female & 2969.96 & 7827.37 & 4745.05 & 4090.87 & 1877.58 & 829.00 & 302.75 & 96.24 & 69.37 & 159.69 & 2.65 & 195.09 \\
\hline & Total & 3472.81 & 8822.24 & 5248.50 & 5012.31 & 2269.82 & 979.52 & 367.36 & 113.15 & 69.61 & 138.76 & 2.73 & 233.09 \\
\hline 2014 & Male & 2273.79 & 9718.80 & 7407.49 & 8532.81 & 4210.74 & 1511.03 & 719.19 & 250.76 & 146.28 & 133.20 & 2.85 & 336.56 \\
\hline & Female & 1823.08 & 7941.76 & 6245.69 & 6565.63 & 3166.08 & 1186.55 & 677.87 & 219.63 & 115.65 & 156.90 & 3.07 & 249.94 \\
\hline & Total & 2060.98 & 8884.03 & 6873.93 & 7599.11 & 3715.69 & 1358.70 & 699.91 & 235.00 & 130.48 & 143.59 & 2.96 & 294.06 \\
\hline 2015 & Male & 4316.09 & $12,573.95$ & 7807.17 & 8861.40 & 4245.72 & 1849.00 & 777.76 & 245.05 & 158.68 & 172.09 & 4.66 & 384.51 \\
\hline & Female & 3234.81 & $10,572.90$ & 6691.21 & 6882.51 & 2928.86 & 1309.86 & 570.57 & 225.67 & 95.49 & 178.61 & 3.40 & 284.78 \\
\hline & Total & 3800.87 & $11,632.01$ & 7289.34 & 7923.10 & 3620.20 & 1595.61 & 680.41 & 235.18 & 126.23 & 174.94 & 4.04 & 335.63 \\
\hline Total & Male & 2129.00 & 6908.65 & 6039.67 & 6011.85 & 2988.52 & 1234.51 & 518.30 & 196.49 & 134.50 & 116.51 & 3.14 & 273.29 \\
\hline & Female & 1550.78 & 5348.04 & 4621.60 & 4444.30 & 2163.41 & 911.50 & 397.29 & 164.48 & 103.55 & 123.18 & 2.78 & 197.01 \\
\hline & Total & 1852.57 & 6167.17 & 5368.42 & 5264.54 & 2595.02 & 1081.28 & 460.94 & 180.85 & 119.39 & 119.44 & 2.96 & 236.11 \\
\hline
\end{tabular}

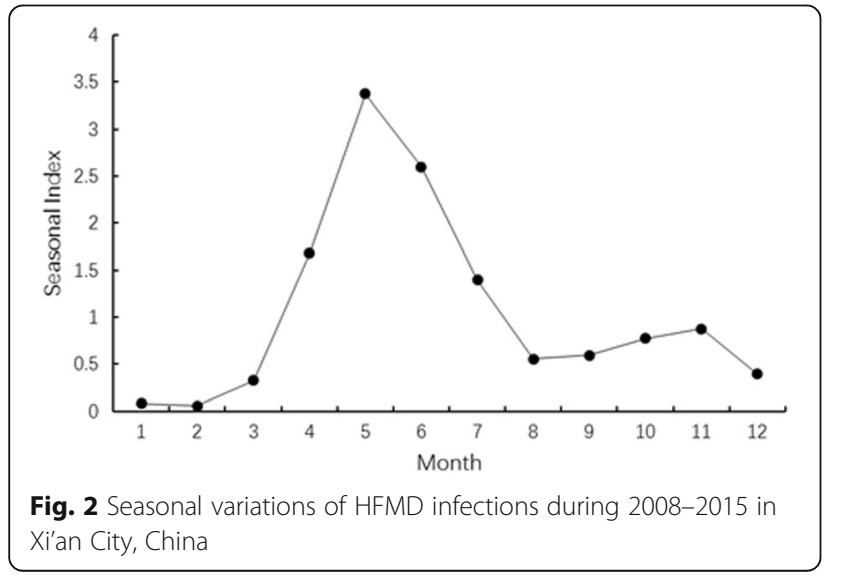

\section{Enterovirus serotype distribution}

A total of 2859 HFMD cases were confirmed in the laboratory, of which $1641(57.40 \%)$ cases were infected by EVA71, 719 cases $(25.14 \%)$ by CVA16, and 499 cases $(17.45 \%)$ by untyped enteroviruses (UEV) (Table 5).These cases were from the surveillance test program. The incidence rate Incidence of HFMD infection per 100,000 by these three enterovirus serotype through 2008-2015 were 2.49(EV71), 1.44(CVA16), 2.19(UEV) (Table 4).

The annual proportion of HFMD cases infected by these 3 serotypes was not consistent from 2008 to 2015 (Fig. 5). During 2011 and 2015, EVA71 was the primary attacking enterovirus, accounting for $50.0 \%$ of all infection. EVA71 caused highest number of fatalities $(0.91 \%)$, while UEV caused the most severe cases (45.89\%) (Table 5). 


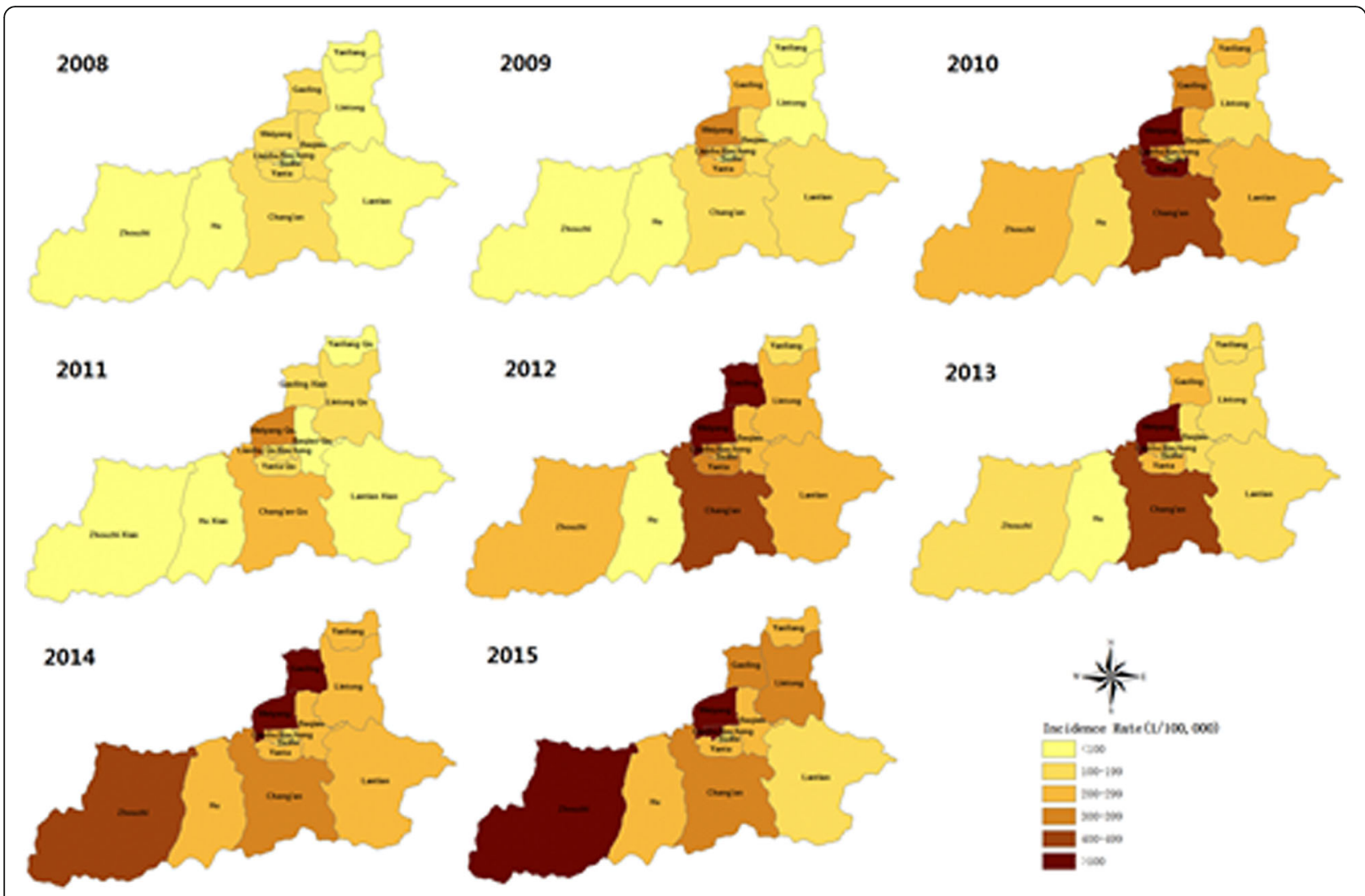

Fig. 3 Spatial trend of HFMD incidence based on annual incidence rate at the county level during 2008-2015 in Xi'an City, China

\section{Discussion}

The study confirmed that Xi'an city was a major center of HFMD infections after compare the average incidence rate with other capital cities and listed the higher IR cities here such as Beijing ( $I R=164.07 / 100,000$, during 2007-2015) [13] Wuhan(IR = 147.45/100,000,during 2011-2016) [14], Taiyuan $(I R=166.64 / 100,000$, during 2012-2014) [15], Shenyang $(\mathrm{IR}=116.04 / 100,000$, during 2012-2016) [16], Tianjin(IR = 116.41/100,000, during 2013-2014) [17], and for Xi'an, it has an average annual incidence rate of 235.01 per 100,000 population which is higher than most capital cities in the national wide. Also, the epidemic tendency is consistent with previous reports in China [18, 19], Children, especially boys younger than 5 years, were the most vulnerable group. In Xi'an, the largest seasonal outbreak occurred during April and July, followed by a smaller peak during September and November. We also observed that central regions of Xi'an city were the major area of the HFMD outbreaks. EVA71 was the predominant enterovirus serotype causing HFMD.

Xi'an has a high incidence rate and lower case fatality rate comparing with the national wide. The national

Table 3 Incidence of HFMD infection per 100,000 by year and region

\begin{tabular}{lllllllllllllll}
\hline & Xincheng & Beilin & Lianhu & Baqiao & Weiyang & Yanta & Yanliang & Lintong & Chang'an & Lantian & Zhouzhi & Hu & Gaoling & Total \\
\hline 2008 & 82.84 & 77.00 & 130.48 & 107.48 & 191.89 & 143.00 & 39.98 & 85.12 & 109.95 & 33.03 & 8.21 & 37.60 & 127.55 & 91.68 \\
2009 & 152.32 & 86.09 & 221.47 & 154.29 & 335.20 & 260.88 & 61.22 & 63.64 & 151.81 & 127.15 & 45.59 & 53.27 & 246.26 & 149.14 \\
2010 & 254.85 & 188.81 & 334.98 & 279.83 & 663.57 & 566.28 & 229.80 & 149.14 & 499.06 & 277.66 & 214.15 & 105.08 & 378.90 & 325.40 \\
2011 & 143.28 & 138.44 & 180.24 & 98.63 & 250.37 & 180.65 & 97.63 & 124.41 & 231.53 & 72.95 & 44.07 & 26.60 & 115.75 & 146.35 \\
2012 & 236.97 & 237.55 & 352.53 & 248.00 & 454.08 & 325.00 & 112.19 & 219.28 & 458.53 & 227.04 & 220.77 & 99.89 & 502.00 & 297.98 \\
2013 & 145.72 & 178.06 & 229.92 & 190.28 & 367.63 & 267.31 & 147.06 & 135.71 & 433.95 & 148.91 & 135.94 & 84.84 & 236.11 & 233.09 \\
2014 & 156.09 & 177.79 & 229.30 & 274.30 & 476.01 & 229.23 & 260.49 & 271.40 & 359.26 & 218.69 & 412.16 & 244.24 & 515.23 & 294.06 \\
2015 & 195.21 & 234.03 & 251.82 & 310.60 & 516.46 & 270.90 & 287.44 & 324.70 & 462.70 & 207.40 & 548.19 & 268.06 & 366.18 & 335.63 \\
Total & 171.07 & 161.92 & 241.54 & 209.49 & 408.62 & 274.01 & 156.15 & 170.54 & 339.85 & 163.54 & 200.00 & 114.89 & 319.06 & 236.11 \\
\hline
\end{tabular}




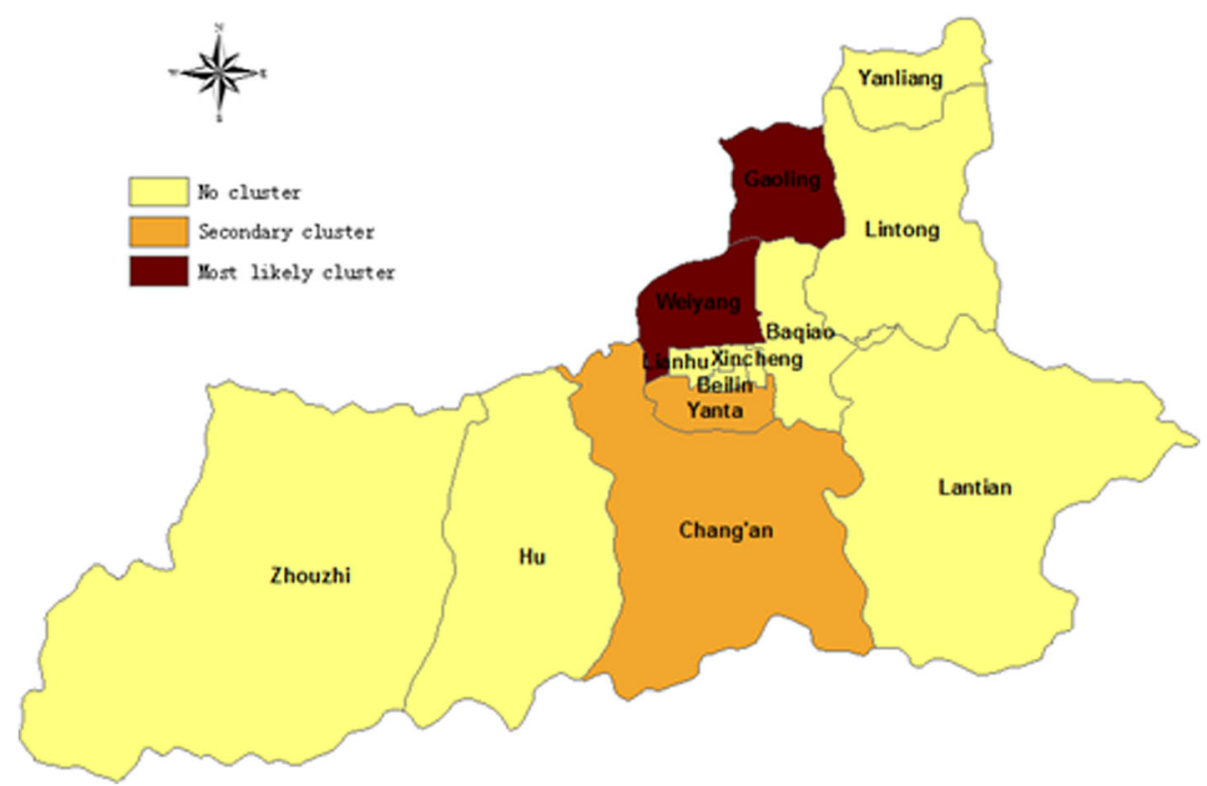

Fig. 4 Spatial distribution of clusters with high HFMD risk during 2008-2015 in Xi'an City, China

incidence of HFMD in China during 2010-2012 was reported 1.2 per 1000 person-years [2]. Our study observed that the estimated incidence rate of HFMD infections in Xi'an city during 2010-2012 was higher than the average national level. Although the incidence rate of HFMD in Xi'an was high with an increasing temporal trend, the case fatality rate was however declining. In May 2008, China established the national surveillance system for HFMD, in order to improve the case- finding ability and reduce the case failed to report. Control and prevention of HFMD.

The highest outbreaks of HFMD in Xi'an City were observed during April through July, followed by September and November, which was consistent with results reported in other areas of China. In Zunyi city, the highest incidence rates of HFMD infection occurred during May-July and October-December [20]. In Guangxi Province, the highest rate occurred during April-July [8]. And in

Table 4 Incidence of HFMD infection per 100,000 by enterovirus serotype

\begin{tabular}{lllll}
\hline & EV 71 & CV A16 & UEV & Total \\
\hline 2008 & 0.10 & 0.09 & 0.03 & 0.22 \\
2009 & 1.15 & 0.16 & 0.10 & 1.41 \\
2010 & 1.37 & 1.65 & 0.71 & 3.73 \\
2011 & 1.50 & 0.19 & 0.61 & 2.30 \\
2012 & 4.86 & 1.36 & 1.46 & 7.68 \\
2013 & 1.95 & 1.59 & 6.94 & 10.49 \\
2014 & 5.62 & 3.75 & 1.36 & 10.73 \\
2015 & 2.90 & 2.47 & 5.69 & 11.06 \\
Total & 2.49 & 1.44 & 2.19 & 6.12 \\
\hline
\end{tabular}

Guangdong Province, the highest seasonal incidences was May-June and October-November [6]. Temperature and climate influence the viral activity [21], and consequently, may be associated with the chance of infection in susceptible populations. These results implicate that control and prevention shall be launched before the anticipated peak of seasonal infections of HFMD in Xi'an.

This study also revealed that the areas of high RR of HFMD were the central regions of Xi'an located around the urban region, specifically Weiyang District, Gaoling County, Yanta District, and Chang'an District. This finding indicates the need to focus HFMD control and prevention measures in central Xi'an, to make the allocation of public health resources most cost-effective and beneficial.

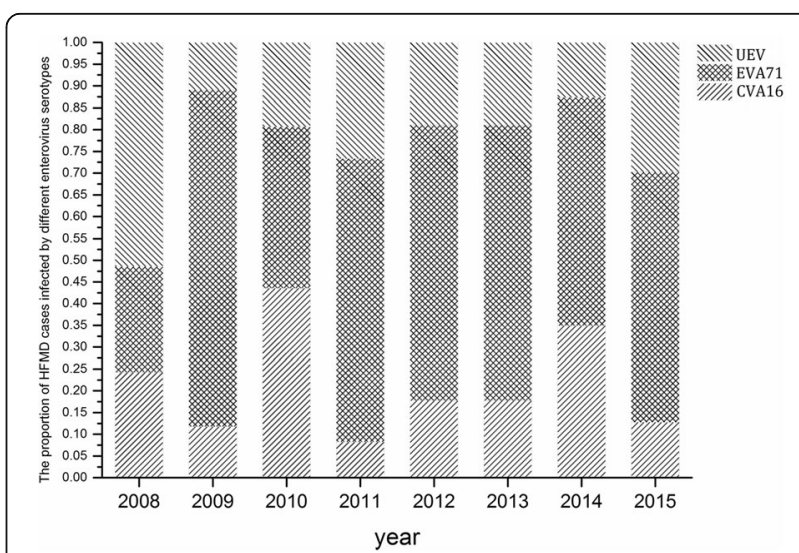

Fig. 5 Proportion of HFMD cases infected by 3 enterovirus serotypes during 2008-2015 in Xi'an City, China 
Table 5 Disease features of the three serotypes of enterovirus in Xi'an City, China during 2008-2015

\begin{tabular}{lllll}
\hline & $\begin{array}{l}\text { Laboratory- } \\
\text { confirmed }\end{array}$ & Median age, y & Fatalities & Severe \\
\hline EV-A71 & $1641(57.40 \%)$ & 2.00 & $15(0.91 \%)$ & $710(43.27 \%)$ \\
CV-A16 & $719(25.15 \%)$ & 2.00 & $1(0.14 \%)$ & $95(13.21 \%)$ \\
UEV & $499(17.45 \%)$ & 2.00 & 0 & $229(45.89 \%)$ \\
\hline
\end{tabular}

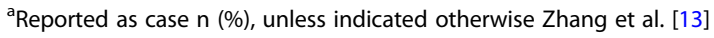

There is one limitation in our study, which is about the dominant etiological pathogens. Before 2012, EVA71 and CVA16 were the predominant etiological pathogens of HFMD among young children in China [1]. In recent years, the pathogens responsible for HFMD infections in China have become more diverse; the percentages of EVA71 and CVA16 infection have decreased, while that of CVA16 has increased in some areas of China [22-25]. But in Xian, only the serotypes EVA71 and CVA16 were detected, and other serotypes were defined as untyped enteroviruses (UEV), and our laboratory did not has the reagent to test other serotypes such as CA6 and CA10 which also be the high incidence serotypes in China recent years. This might be insufficient in our study and future study could complement this part.

The present study showed that, although the proportion of cases infected by UEV fluctuated, EVA71 was still the predominant pathogen of HFMD in Xian City. It was reported that EVA71-associated HFMD cases are more likely than those of other serotypes to develop potentially fatal neurological and systemic complications [26]. This study also showed that the fatality rate in EVA71-associated HFMD cases was higher than that of other serotype-associated HFMD cases. Therefore, we should focus on control and prevention of EVA71-associated HFMD, and monitor closely the fluctuations of other serotype-associated HFMD infections.

Meanwhile, the first EVA71 vaccine has now launched in China. The vaccine could give more than $90 \%$ protection against clinical EVA71-associated HFMD [27, 28], which should assist with the control and prevention of HFMD in Xi'an.

This study also observed that the incidence rate of HFMD infections in Xian City was high for boys younger than 5 years, which is consistent with previous reports in other areas of China [2, 7, 20, 29, 30]. Therefore, we should focus HFMD programs for control and prevention on children who are aged less than 5 years, especially boys.

It should also be noted that China established the national surveillance system for HFMD in May 2008. Therefore, the number of HFMD cases and deaths from January to April in 2008 may be under-reported. Another limitation of this study was that only a few samples were tested for enteroviruses, and specific serotypes other than EVA71 and CVA16 were not tested in Xi'an. Studies are needed to monitor the fluctuation in HFMD infections in Xian over longer periods, and more samples should be tested to identify comprehensively the serotypes of enteroviruses.

In summary, the current study confirmed that children, especially boys under the age of 5 years, were the group most susceptible to HFMD infection. The seasonal outbreaks in Xi'an occur from April through July and from September through November. We also observed that the central regions of Xi'an city were the major locations of infections. These findings can be helpful for the prevention and control of HFMD infections in the future.

\section{Conclusion}

From the study, we come to the conclusion that HFMD morbidity rate was increasing by years, and mortality rate was decreasing respectively in Xi'an Northwest China. Furthermore, EV71 is the primary attacking entervirus since 2011 and composed $50 \%$ of all the infection cases. The result pointed out that season, region and focus groups should be considered priority to control the developments of the epidemics. Children who under 5 years old is the adaptation people to receive vaccination, which means by promoting the vaccine injection, severe cases and death cases will be decreased.

\section{Abbreviations}

CDC: Center for Disease Control and Prevention; CVA16: Coxsackie virus A16; EVA71: Enteroviruses A71; HFMD: Hand-foot-and-mouth disease;

PCR: Polymerase Chain Reaction

\section{Acknowledgments}

We are grateful to the anonymous reviewers for their valuable comments, suggestions, and critical reviews of the current manuscript.

\section{Funding}

This study was financially supported by the National Science Foundation of China (No. 81573104, 81773372, 30972517, 81373058). No. 81573104 supported the data collection and data analyzing work; No.81773372 supported the laboratory testing work; No.30972517 and No.81373058 supported the interpretation and writing manuscript work.

\section{Availability of data and materials}

HFMD cases data from the study is not public and confidentially, declared by Xi'an CDC. This study got the permission of use and analysis of these data from Xi'an CDC. The demographic data of each county and district during 2008-2015 were also collected from Xi'an Bureau of Statistics. The population size was estimated from annual household registration records maintained by the local police departments. Xi'an CDC has got the cooperation with the local police department and government organization to access the population size data and use it in surveillance system and research work. In this study, it could be get online through the Xi'an CDC disease surveillance system. All patients' data analyzed in this study was rendered anonymous prior to analysis. Public data used or analyzed during the study are available from the corresponding author on reasonable request.

\section{Authors' contribution}

All authors have read and approved this manuscript and have no competing interests. LJF collected the data and designed the study plan, written the paper. XXM analyzed the distribution of incidence population. PZS did the data colleting work and helps on designing the data collecting form. LY designed the analysis method. XD analyzed the incidence rate among years. ZWL analyzed the age composition in. LQ did the etiological analysis. LXT analyzed the seasonal factors. LSY analyzed the regional cluster distribution. SZJ designed the survey plan. YXL assisted data collection work and helps on the data cleaning work. XYM is the corresponding author who in charge of the study design and control the study progress. 


\section{Ethics approval and consent to participate}

The Ethics Committee of Fourth Military Medical University (Grant No.: 2015018) approved this study. The study has got the written consent to participate from the participants. Data analyzed in this study were previously gathered and had been de-identified. Data is got from Xi'an CDC disease surveillance system which is not public, and this study got the written permission of use these data from Xi'an CDC.

\section{Consent for publication}

Not Applicable.

\section{Competing interests}

The authors declare that they have no competing interests.

\section{Publisher's Note}

Springer Nature remains neutral with regard to jurisdictional claims in published maps and institutional affiliations.

\section{Author details}

'Institute of Endemic Diseases of School of Public Health, Health Science Center, Key Laboratory of Trace Elements and Endemic Diseases of National Health and Family Planning Commission, Xi'an Jiaotong University, No.76, YanTa West RD, Xi'an 710061, Shaanxi, China. ${ }^{2}$ Xi'an Center for Maternal and Child Care Service, Fourth Military Medical University, No.73, Xi'an West Street, Xi'an 710002, Shaanxi, China. ${ }^{3}$ Department of Epidemiology, School of Public Health, Fourth Military Medical University, No. 17, Changle West RD, Xi'an 710032, Shaanxi, China. ${ }^{4}$ Center of Disease Control and Prevention of Xi'an, Shaanxi Province, China; No,599 Xiying Rd, Xi'an 710054, Xi'an 710061, Shaanxi, China.

\section{Received: 15 March 2018 Accepted: 17 December 2018}

\section{Published online: 07 January 2019}

\section{References}

1. Yi L, Lu J, Kung HF, He ML. The virology and developments toward control of human enterovirus 71. Crit Rev Microbiol. 2011;37(4):313-27.

2. Xing W, Liao Q, Viboud C, Zhang J, Sun J, Wu JT, Chang Z, Liu F, Fang VJ, Zheng Y, et al. Hand, foot, and mouth disease in China, 2008-12: an epidemiological study. Lancet Infect Dis. 2014;14(4):308-18.

3. Hu Y, Xiao G, Guo Y, Yu S, Ma J. The epidemic features of the hand, foot and mouth disease during 2008-2011 in China. Chinese Journal of Disease Control and Prevention. 2014;18(8):693-7 747.

4. Yang F, Yu S, Zhang J, Xiao G. J M: Epidemiology of severe hand foot and mouth disease in the mainland of China, 2008-2011. Disease Surveillance. 2013;28(11):888-93.

5. Zeng H, Lu J, Zheng H, Yi L, Guo X, Liu L, Rutherford S, Sun L, Tan X, Li H, et al. The epidemiological study of Coxsackievirus A6 revealing hand, foot and mouth disease epidemic patterns in Guangdong, China. Sci Rep. 2015 5:10550.

6. Deng T, Huang Y, Yu S, Gu J, Huang C, Xiao G, Hao Y. Spatial-temporal clusters and risk factors of hand, foot, and mouth disease at the district level in Guangdong Province, China. Plos One. 2013;8(2):e56943.

7. Chen S, Qiu L, Jin Y, Du Z, Huang F, Li D, Et A. Prevalent characteristics of hand-foot-mouth disease in Hainan Province, during 2009-2012. China Trop Med. 2014;14(7):803-5.

8. Wu X, Fu Z, Deng G. The epidemiological characteristics of hand-footmouth disease in Guangxi Province, during 2008-2011. Chinese Primary Health Care. 2013;27(2):65-6.

9. Yu H, Guo X, Qiu L, Li H, Zhu N. Epidemiology of hand foot and mouth disease in Shaanxi, 2008-2011. Disease Surveillance. 2012;27(6):443-5.

10. Statistics XABO. Xi'an statistical yearbook. In. Beijing. China: China Statistics Press; 2014. p. 2015.

11. Li N. An outbreak of hand foot and mouth disease in a kindergarten in Xi'an City. Anhui Medical and Pharmaceutical Journal. 2015;19(10):1941-3.

12. Lu J, Geng Y, Weng G. An outbreak of hand foot and mouth disease in a kindergarten. Modern Medicine \& Health. 2012;20(28):3083-5.

13. Zhang Y, Wei Z, Li G. Epidemiological analysis of hand -foot-mouth disease in Beijing,2007-2015. Modern Preventive Medicine. 2017:44(15):2689-99.

14. Zou J, Yang X, Kong D, Wang P. Epidemic characteristics and tendency prediction of hand foot mouth disease in Wuhan(2011-2016). J Public Health and Preventive Medicine. 2017;28(4):46-8.
15. Guo J. Analysis on epidemiological characteristics of hand-foot-mouth disease, Taiyuan city, 2012-2014. Preventive Medicine Tribune. 2016;22(6):433-5.

16. Qi Y, An X, Chen Y, Wang B, Chen H. Analysis on epidemiological characteristics of hand-foot-mouth disease, Shenyang city,2012-2016. Preventive Medicine Tribune. 2018;24(1):35-8.

17. Chen Q, Dong X, Sun M. Epidemiology of hand foot and mouth disease in Tianjin, 2013-2014. Disease Surveillance. 2015;30(6):463-7.

18. Liu Y, Wang X, Liu Y, Sun D, Ding S, Zhang B, Du Z, Xue F. Detecting spatialtemporal clusters of HFMD from 2007 to 2011 in Shandong Province, China. Plos One. 2013;8(5):e63447.

19. Zhuang Z, Kou Z, Bai Y, Cong X, Wang L, Li C, Zhao L, Yu X, Wang Z, Wen $H$. Epidemiological research on hand, foot, and mouth disease in mainland China. Viruses. 2015;7(12):6400-11.

20. Zhang W, Huang B, She C, Liu Y, Tong H, Wang F, Wu K. An epidemic analysis of hand, foot, and mouth disease in Zunyi, China between 2012 and 2014. SAUDI MED J. 2015;36(5):593-8.

21. Coates SJ, Davis M, Andersen LK. Temperature and humidity affect the incidence of hand, foot, and mouth disease: a systematic review of the literature - a report from the International Society of Dermatology Climate Change Committee. Int J Dermatol. 2018.

22. Lu J, Zeng H, Zheng H, Yi L, Guo X, Liu L, Sun L, Tan X, Li H, Ke C, et al. Hand, foot and mouth disease in Guangdong, China, in 2013: new trends in the continuing epidemic. Clin Microbiol Infect. 2014;20(7):0442-5.

23. Xu M, Su L, Cao L, Zhong H, Dong N, Xu J. Enterovirus genotypes causing hand foot and mouth disease in Shanghai, China: a molecular epidemiological analysis. BMC Infect Dis. 2013;13:489.

24. Han JF, Xu S, Zhang Y, Zhu SY, Wu DL, Yang XD, Liu H, Sun BX, Wu XY, Qin CF. Hand, foot, and mouth disease outbreak caused by coxsackievirus A6, China, 2013. J Inf Secur. 2014;69(3):303-5.

25. Hongyan G, Chengjie M, Qiaozhi Y, Wenhao H, Juan L, Lin P, Yanli X, Hongshan W, Xingwang L. Hand, foot and mouth disease caused by coxsackievirus A6, Beijing, 2013. Pediatr Infect DIS J. 2014;33(12):1302-3.

26. Ooi MH, Wong SC, Lewthwaite P, Cardosa MU, Solomon T. Clinical features, diagnosis, and management of enterovirus 71. Lancet neurol. 2010;9(11):1097-105.

27. Li R, Liu L, Mo Z, Wang X, Xia J, Liang Z, Zhang Y, Li Y, Mao Q, Wang J, et al. An inactivated enterovirus 71 vaccine in healthy children. N Engl J Med. 2014:370(9):829-37.

28. Zhu F, Xu W, Xia J, Liang Z, Liu Y, Zhang X, Tan X, Wang L, Mao Q, Wu J, et al. Efficacy, safety, and immunogenicity of an enterovirus 71 vaccine in China. N Engl J Med. 2014;370(9):818-28.

29. Zhou X, Zhu Q, Xia W, He F, Hu M, Ni X, Gao M, Chen H, Chen S. Molecular epidemiology of an outbreak of hand, foot, and mouth disease associated with subgenotype C4a of enterovirus A71 in Nanchang, China in 2014. J Med Virol. 2015;87(12):2154-8.

30. Zhou X, Ma T, Liu J, Wang Z, Pang C. Epidemiological characteristics of hand foot and mouth disease in Qionghai. China Trop Med. 2014;14(3):360-1.

Ready to submit your research? Choose BMC and benefit from:

- fast, convenient online submission

- thorough peer review by experienced researchers in your field

- rapid publication on acceptance

- support for research data, including large and complex data types

- gold Open Access which fosters wider collaboration and increased citations

- maximum visibility for your research: over $100 \mathrm{M}$ website views per year

At BMC, research is always in progress.

Learn more biomedcentral.com/submission 